This item was submitted to Loughborough's Research Repository by the author.

Items in Figshare are protected by copyright, with all rights reserved, unless otherwise indicated.

\title{
Crystallinity control in parts produced from stereolithography injection mould tooling
}

PLEASE CITE THE PUBLISHED VERSION

PUBLISHER

Professional Engineering Publishing / @ IMECHE

VERSION

VoR (Version of Record)

LICENCE

CC BY-NC-ND 4.0

\section{REPOSITORY RECORD}

Harris, Russell A., Richard J.M. Hague, and Phill M. Dickens. 2019. "Crystallinity Control in Parts Produced from Stereolithography Injection Mould Tooling”. figshare. https://hdl.handle.net/2134/4716. 
This item was submitted to Loughborough's Institutional Repository (https://dspace.lboro.ac.uk/) by the author and is made available under the following Creative Commons Licence conditions.

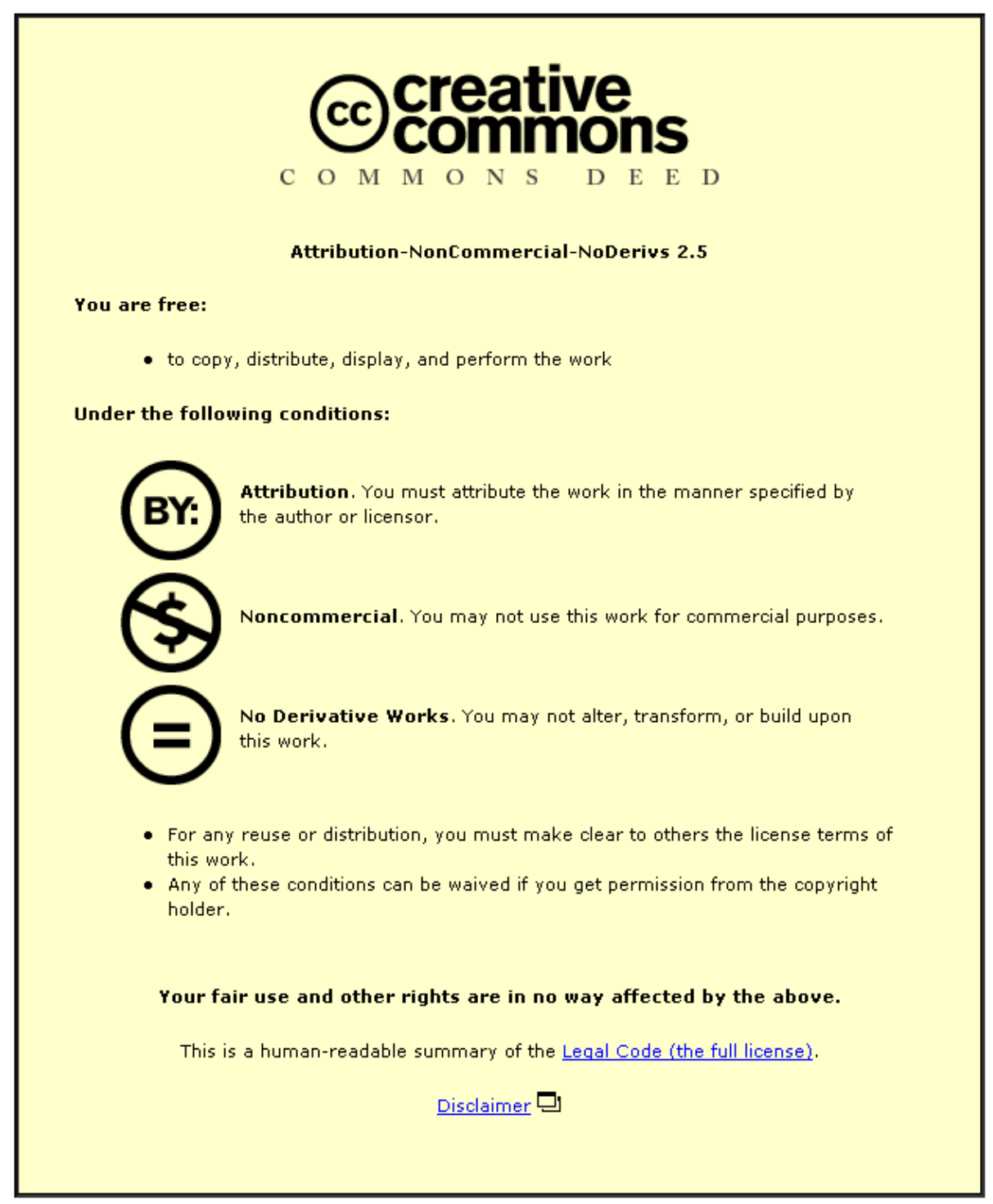

For the full text of this licence, please go to: http://creativecommons.org/licenses/by-nc-nd/2.5/ 


\title{
Crystallinity control in parts produced from stereolithography injection mould tooling
}

\author{
R A Harris*, R J M Hague and P M Dickens \\ Rapid Manufacturing Research Group, Loughborough University, Loughborough, UK
}

\begin{abstract}
The use of moulds produced by stereolithography (SL) for injection moulding provides a quick route to manufacturing a low volume of parts without expensive hard tooling. However, these parts have been shown to exhibit different material property characteristics than those produced from metal tooling. The aim of the present work is to research methods that would allow SL moulds to produce parts of similar material property characteristics to those from conventional metal tools. This work has identified that the different part characteristics are due to differing levels of crystallinity developed in the parts from the comparative mould varieties (SL and metal). These crystallinity differences have been associated with the cooling rates imparted owing to the thermal properties of the mould material. The latter part of this work concerns controlling and manipulating this degree of crystallinity. After a discussion of possible methods, two approaches are taken to modifying the crystalline content of parts produced by SL moulds. One of the approaches is material based, the other concerns the injection moulding process. Differential scanning calorimetry (DSC) is used to quantify the resulting levels of crystallinity in the parts. The results show that by process modification it is possible to produce parts by SL moulding that possess a similar crystalline content to those moulded from metal tooling. The use of modified materials allows parts created in SL and metal tools to be of a consistent crystalline content. The work concludes that not only are SL moulds capable of producing parts that are more like those from metal moulds but also present some unique opportunities that have been demonstrated to be unachievable in metal moulds.
\end{abstract}

Keywords: stereolithography, rapid tooling, plastic injection moulding, crystallinity, differential scanning calorimetry

\section{BACKGROUND}

\subsection{Rapid prototyping and stereolithography}

Stereolithography (SL) is a rapid prototyping (RP) process. $\mathrm{RP}$ processes directly produce a physical geometry from data derived from a three-dimensional representation [i.e. three-dimensional computer aided design (CAD)], and they are characterized by generating the geometry using an additive, layer-by-layer manufacturing sequence, which when initiated runs unattended. SL is the most mature commercial RP process, with its development beginning in the mid-1980s. SL represents one of the most geometrically accurate commercial RP processes, with a minimum feature size of approximately $0.1 \mathrm{~mm}$ possible. SL generates a solid object by selectively curing a photosensitive liquid resin by exposure to UV light provided by laser. The part is

The MS was received on 13 March 2003 and was accepted after revision for publication on 18 July 2003.

*Corresponding author: Rapid Manufacturing Research Group, Wolfson School of Mechanical and Manufacturing Engineering, Loughborough University, Loughborough, Leicestershire LE11 3TU, UK. generated section by section on a platform that is contained within the bath of the liquid resin. The materials that can be used in the process are restricted to acrylic and epoxy resins. Resins of very different characteristics are available, but they are all essentially variants of epoxy and acrylic (in this work epoxy is used).

\subsection{Plastic injection moulding}

Plastic injection moulding is a manufacturing process that broadly consists of forcing a molten polymer into an enclosed shaped cavity to reproduce a definite form. When the form cools and hardens, it is ejected and the cycle is repeated to produce multiple pieces.

\subsection{Stereolithography tooling for injection moulding}

The introduction of RP has allowed engineers and designers to generate physical models of required parts very early in the design and development phase. However, the requirements of such prototypes has now progressed beyond the validation of 
geometries and on to the physical testing and proving of the parts. For such tests to be conducted, the part must be produced in the material and by the process intended for the production intent part. For injection moulded parts this situation highlights the requirement of a rapid mould making system that can deliver these parts within the time and cost boundaries.

Stereolithography allows for rapid, direct generation of tooling inserts that can be used in injection moulding. The accuracy of the SL RP process results in inserts that require few further operations prior to their use in injection moulding. Thus, the process provides a quick route to tooling that, depending on geometric complexity and the moulding polymer, can produce $\geqslant 50$ parts [1]. The supposed great advantage of the process is that it provides a low volume of parts that are identical to parts that would be produced by conventional hard tooling in a fraction of the time and cost.

The key to successful SL tooling is to understand the demands of the mould design and injection moulding parameters, which are very different from those for metal moulds. It has also been demonstrated that appropriate choices in mould design and process variables can reduce the risk of failure in SL tooling [2-4].

Various polymers have been successfully moulded by SL injection moulding. These include polyester (PE), polypropylene (PP), polystyrene (PS), polyamide (PA), polycarbonate (PC), polyetheretherketone (PEEK), acrylonitrile-styrene acrylate (ASA) and acrylonitrilebutadiene-styrene (ABS) [5-9].

\subsection{Moulded part characteristics}

SL produces parts that consist of epoxy. Thus, the tooling inserts are plastic and possess very different material characteristics compared with their traditional metal counterparts.

The present work was initiated by the finding that crystalline polymer parts produced from SL moulds possess different material properties and characteristics compared with those from a metal tool. The different properties observed in parts produced from SL moulds include:

(a) greater strength and stiffness $[\mathbf{6}, \mathbf{1 0}-\mathbf{1 2}]$,

(b) lower impact strength $[\mathbf{6}, \mathbf{1 1}, \mathbf{1 2}]$,

(c) greater shrinkage $[\mathbf{1 3}]$.

Amorphous polymers exhibited no such differences in physical properties, irrespective of the mould variety.

\section{HYPOTHESIS}

The exhibition of different moulded part properties negates the greatest advantages of the SL injection moulding tooling process; the moulded parts do not replicate parts that would be produced by conventional hard tooling. The hypothesis of the present work was to acquire an understanding of the mechanisms in SL tooling that induce these different part properties and to develop a modification of the process that could change these, allowing the moulded parts to demonstrate characteristics like those produced by conventional means. Should this be possible, SL tooling would be able to provide a truly comparative rapid tooling alternative for low volumes of injection moulded parts. The work is detailed in this paper in two parts. Section 3 covers the identification of the cause of part anomalies, and section 4 describes the approaches taken for crystallinity control.

\section{IDENTIFICATION OF THE CAUSE OF PART ANOMALIES}

\subsection{Introduction}

The differing part properties that have previously been observed in SL tools are heavily dependent on the amount of crystallinity developed in the part during processing [14]. The amount of crystallinity developed is influenced by the rate of cooling of the polymer from its molten state [15-18]. It was suspected that part anomalies were due to differing degrees of crystallinity developed in the parts owing to their thermal history during moulding. SL and metal possess very different heat transfer characteristics and when used as mould tool materials this would result in very different rates of part cooling in the injection moulding process. These theories were examined by quantifying the crystallinity of PA66 parts produced in aluminium (AL) and SL moulds and by evaluating the thermal histories experienced by the parts during moulding.

\subsection{Research methodology}

\subsubsection{Tool design}

The tooling materials to be compared were SL epoxy and aluminium. Aluminium (grade LM24) was chosen as a metal tooling material for comparison as it represents a common tool material choice when a low volume of parts is required on account of the high machining rates possible. The SL moulds were manufactured by a 3D Systems SLA350 machine, using Vantico 5190 resin. The moulded specimen consisted of a bar shape with dimensions of $12.7 \mathrm{~mm}$ by $127 \mathrm{~mm}$, with a wall thickness of $3.2 \mathrm{~mm}$. The tooling cavity was gated at one end, measuring $6.4 \mathrm{~mm}$ in width and $3.2 \mathrm{~mm}$ in depth. No ejection system was utilized in the mould as the parts were simple and easily removed by hand. Illustrations of these moulding cavities are shown in Fig. 1. The mould cavity inserts were contained within a steel bolster which provided alignment of the mould halves, provided material entry into the mould via a tapered sprue bush and protected the inserts from any excessive application of pressure. 

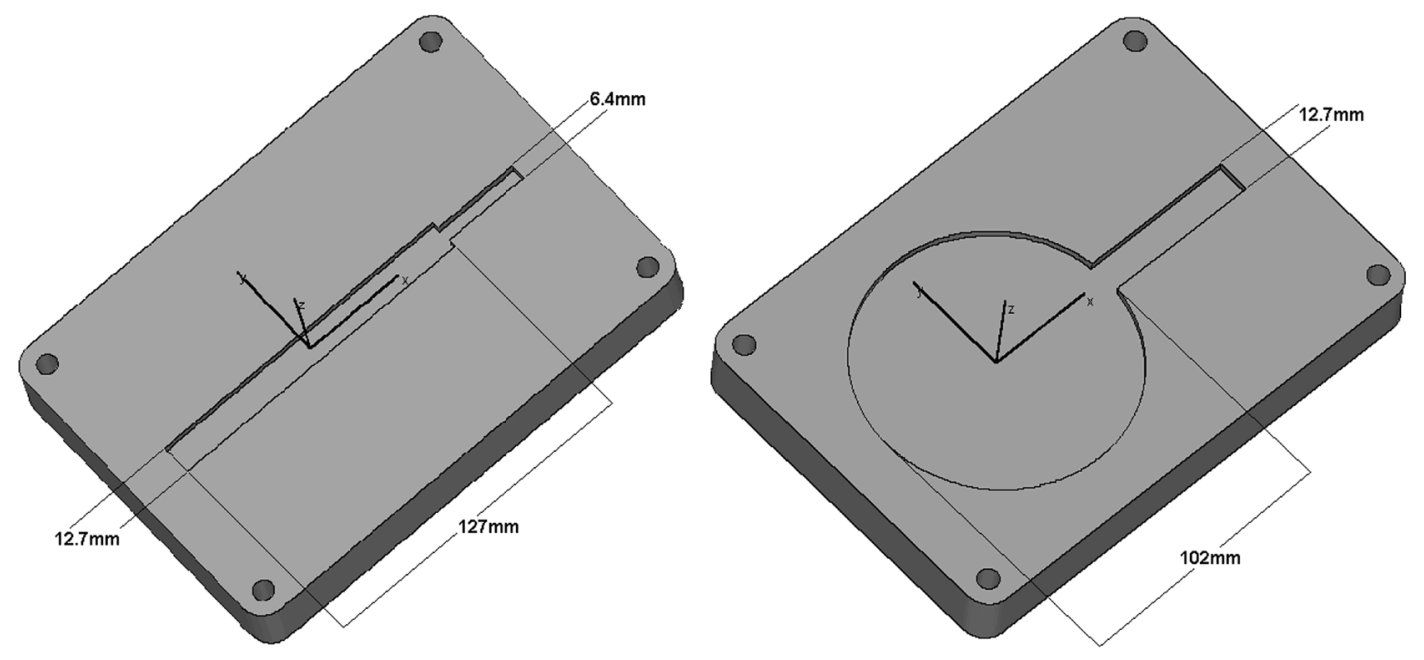

Fig. 1 Illustrations of the different mould cavities employed

\subsubsection{Injection moulding parameters}

Polyamide 66 (PA66) was chosen to represent a crystalline polymer in the experiments. This nylon is a widely used polymer in many plastic products. It was important to ensure that the same injection moulding process parameters were used for both mould types. These parameters were largely dictated by the lower-strength SL mould. The important injection moulding parameters were as follows:

1. The injection speed used was $100 \mathrm{~mm} / \mathrm{s}$.

2. The injection pressure was 150 bar.

3. Upon mould filling, a follow-up pressure of $150 \mathrm{bar}$ was held for $1.5 \mathrm{~s}$.

Twenty mouldings were produced from each mould type. The PA66 used was Bergamid A70NAT produced by PolyOne. The injection moulding machine used was a Battenfeld 600/125 CDC model with a Unilog 4000 control unit.

\subsubsection{Thermal history profiles}

The heat transfer rate imposed by each mould type was established by real-time data acquisition during the moulding cycle. Three k-type thermocouples were inserted evenly along the length of the mould cavity. The probe tips were situated $0.5 \mathrm{~mm}$ below the cavity surface. The fitting of these thermocouples is illustrated in Fig. 2. The signals were read and interpreted by a instruNet data acquisition system, then analysed and recorded with a HP VEE software program. Prior to polymer injection, each mould was at its ambient temperature of $23^{\circ} \mathrm{C}$. The temperature profile was plotted over a period of $10 \mathrm{~min}$.

\subsubsection{Crystallinity analysis}

Differential scanning calorimetry (DSC) was used to measure the degree of crystallinity, $(\chi)$, in the samples. DSC is a thermal analysis technique used for direct measurement of the temperatures and heat flow to a sample during heating in a controlled atmosphere over a period of time. This technique provides quantitative and qualitative information about physical changes by monitoring endothermic or exothermic processes that represent material transitions. The degree of crystallinity is determined by measuring the energy consumed by the melting of the crystalline areas; this is the heat of fusion. A sample heat of fusion is proportional to $\chi$ [19]. The $\chi$ of the sample can be determined by knowing the heat of fusion for the specific sample and ratioing this against the heat of fusion required to melt a completely (100 per cent) crystallized sample of the material [20]. Such a value for PA66 is $200 \mathrm{~J} / \mathrm{g}$ [21].

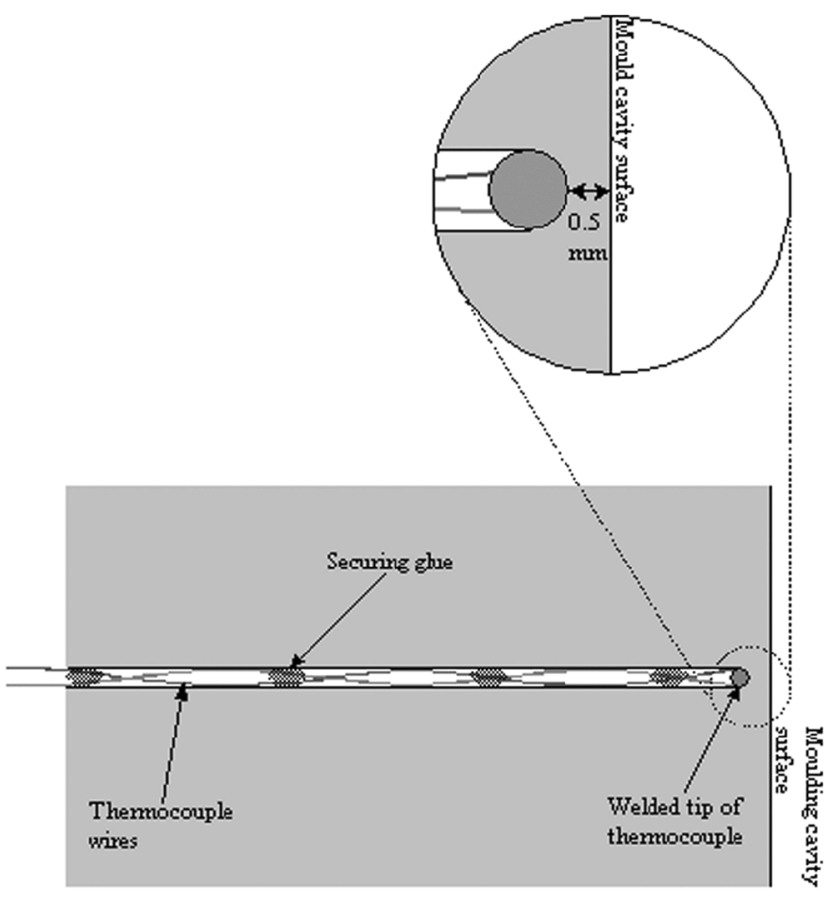

Fig. 2 Cross-sectional illustration of thermocouple insertion 
With both these values it is possible to determine $\chi$ by the equation [22]

$$
\chi=\frac{\Delta H}{\Delta H_{100 \%}}
$$

where

$$
\begin{aligned}
& \chi=\text { degree of crystallinity }(\%) \\
& \Delta H=\text { heat of fusion } \\
& \Delta H_{100 \%}=\text { heat of fusion for } 100 \text { per cent crystallization }
\end{aligned}
$$

The sample taken from each of the mouldings for DSC analysis was of an average weight of $\sim 17 \mathrm{mg}$. The test samples were taken from a central region of each moulding, as shown in Fig. 3. A sample was taken from each of four different mouldings for each test specimen variety to be examined by DSC, and one scan was run on each. The scan could not be repeated on each sample as the thermal history was erased by the analysis through the heating involved. The samples were extracted from the mouldings by cutting with hand clippers/cutters. By using this method, samples were not subjected to heat from mechanical cutting or sawing. The mouldings selected for analysis represented an even distribution of the mouldings that were produced in sequence from each experimental variety. The mouldings examined were numbers 4, 8, 12 and 16 from the set of 20 mouldings produced. The apparatus used was a modulated DSC machine produced by TA Instruments, model 2920. The cell atmosphere was provided by a refrigerated nitrogen cooling system produced by TA Instruments. The temperature range of the DSC analysis used was $100-320^{\circ} \mathrm{C}$. This operating range was derived by observing the temperatures at which transitions occurred during an analysis in a wider temperature range. This temperature range displayed all transitions of interest while consuming a shorter period of time for each analysis when using a heating rate of $10 \mathrm{~K} / \mathrm{min}$.
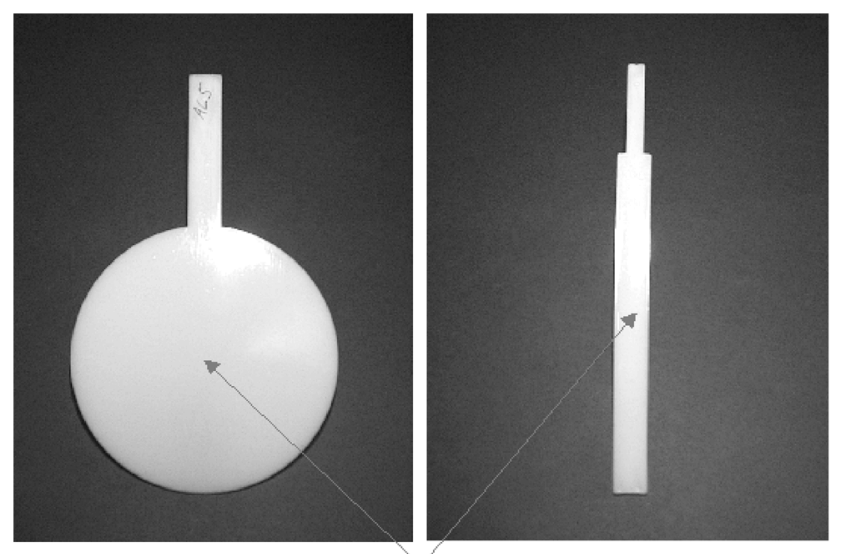

Sample areas

Fig. 3 DSC sample location

\subsection{Results and discussion}

\subsubsection{Thermal history profiles}

The average temperature profiles experienced in the moulds are shown in Fig. 4. The profiles illustrate the vastly different temperature conditions experienced in the SL and AL moulds. The temperature activity in the AL moulds occurred in a very short period of time owing to the material's high thermal conductivity. The temperature profile in the SL mould was more extreme and protracted. Without external assistance (i.e. cooling by compressed air), the SL mould would take $15 \mathrm{~min}$ to return to its ambient temperature.

\subsubsection{Crystallinity analysis}

The DSC results (Table 1, listed as 'Initial') have shown that there was more crystallinity developed in the PA66 parts produced in SL moulds than in those produced from AL moulds. The DSC results also showed a slight difference in the curve characteristics displayed by the AL and SL mouldings. The AL samples demonstrated an exotherm prior to the heat of fusion (endotherm), while none of the SL samples showed this in the DSC tests. This exotherm

Average temperature profiles for AL \& SL moulds

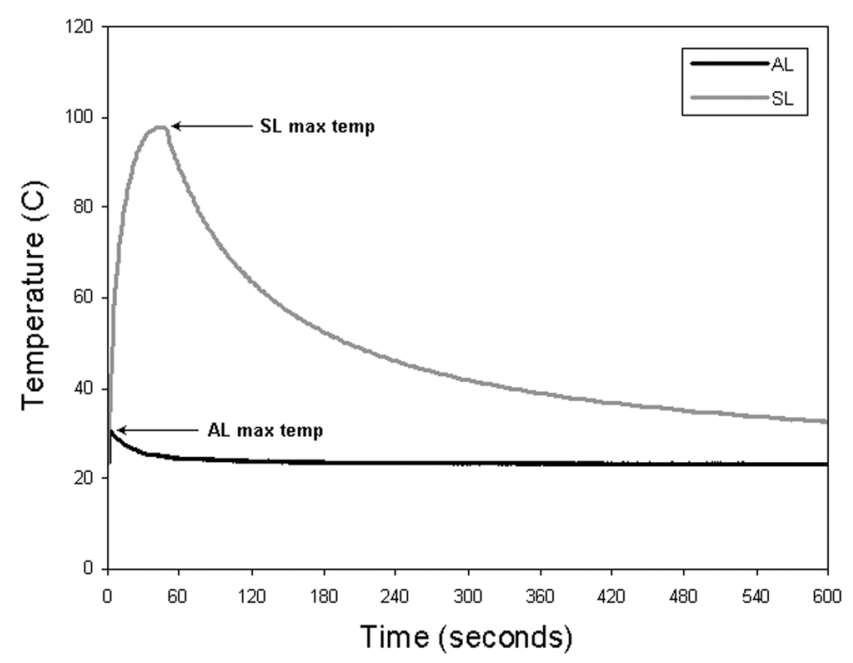

Fig. 4 Mould temperature profiles

Table 1 Per cent of $\chi$ results

\begin{tabular}{llll}
\hline Sample & Initial & Nuc. agent & Temp. mod. \\
\hline AL 1 & 20.75 & 24.99 & 21.56 \\
AL 2 & 21.84 & 24.29 & 21.05 \\
AL 3 & 21.74 & 24.8 & 21.65 \\
AL 4 & 22.03 & 23.73 & 21.34 \\
SL 1 & 28.42 & 24.97 & 22.14 \\
SL 2 & 27.86 & 24.23 & 22.32 \\
SL 3 & 27.39 & 24.58 & 22.45 \\
SL 4 & 28.15 & 24.31 & 22.31 \\
\hline
\end{tabular}


DSC

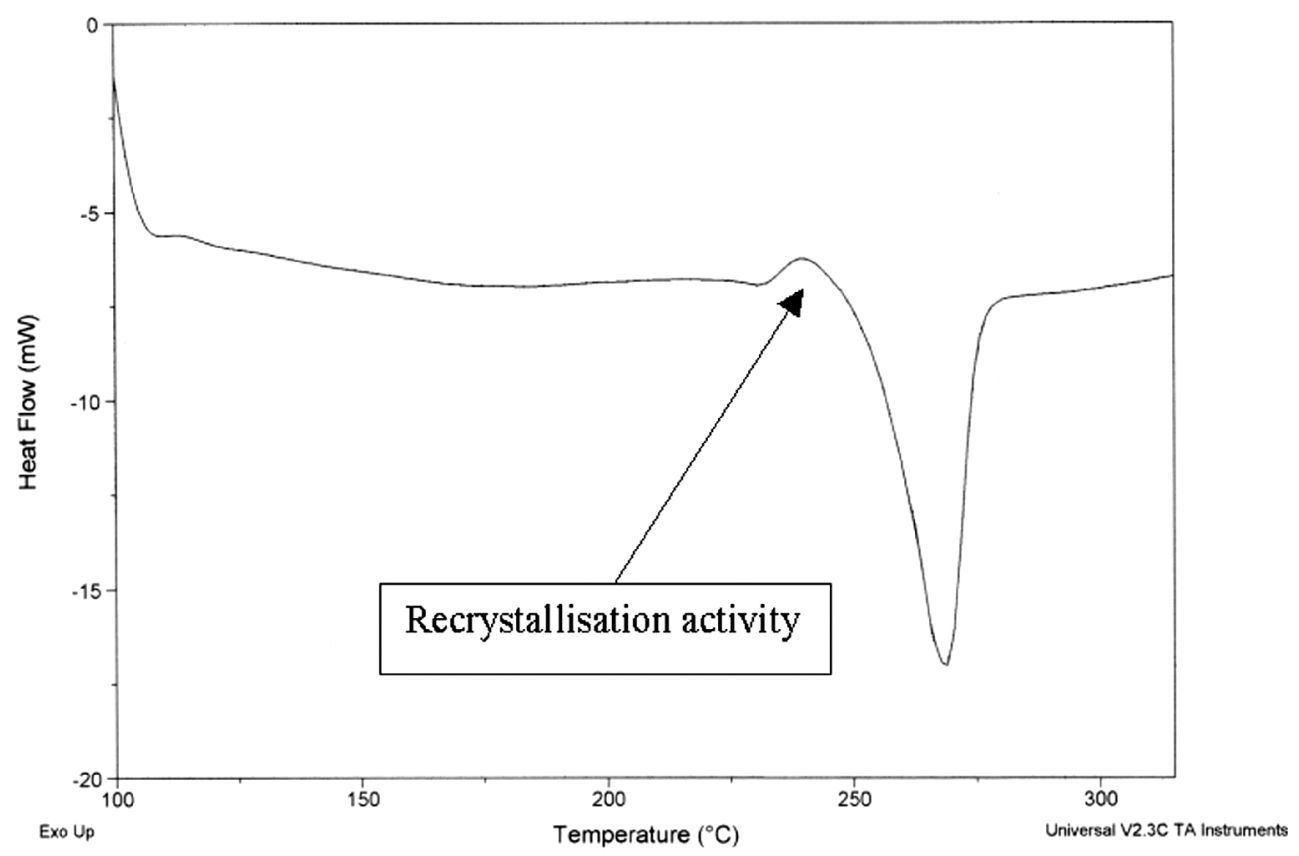

Fig. 5 Example of the initial DSC curve from an AL mould

was due to the development of further crystallinity (recrystallization) during heating in the DSC tests. This is illustrated in the examples shown in Figs 5 and 6 . The absence of any recrystallization activity in the samples from the SL mould indicates that the level of $\chi$ in the sample was already at its maximum as a result of its prior conditioning.

The only injection moulding process variable in the experiments was the different cooling rate of the part

\section{DSC}

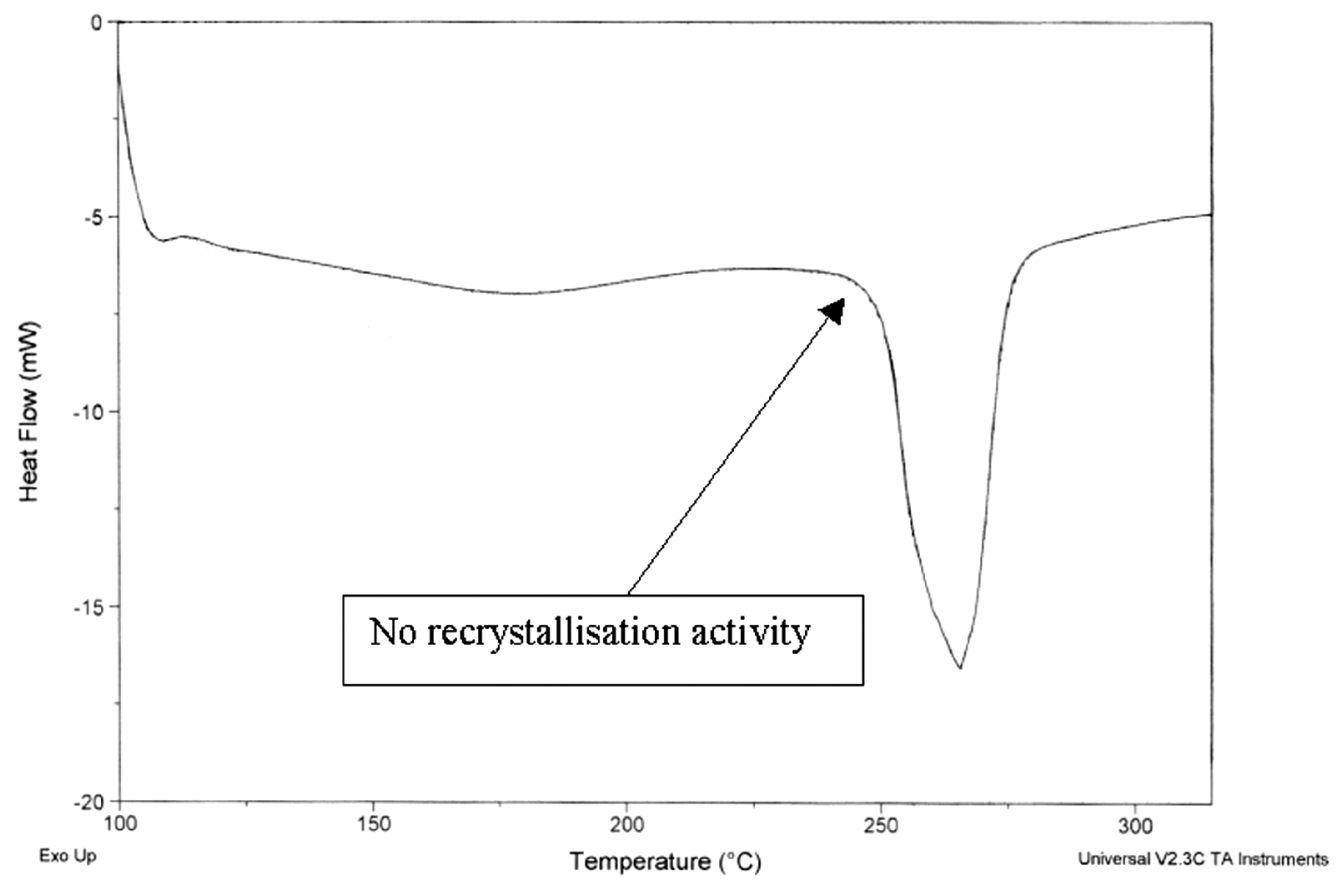

Fig. 6 Example of the initial DSC curve from an SL mould 
which was imposed by the heat transfer properties of the mould, as illustrated by the thermal history profiles. It can be deduced that the difference in $\chi$ of the parts was due to these different cooling rates.

\section{APPROACHES TAKEN FOR CRYSTALLINITY CONTROL}

\subsection{Introduction}

Since it has been identified that the crystallinity differences in the parts were due to the cooling rate imposed by the inherent heat transfer properties of the mould material, it seems logical that, in order to achieve equal crystallinity, an attempt should be made to make these heat transfer characteristics more like those of metal moulds. However, being able to increase the heat transfer properties a thousand times so that they are like those of their aluminium counterpart (thermal conductivity: $\mathrm{SL}=0.2 \mathrm{~W} / \mathrm{m}-\mathrm{K}$, $\mathrm{AL}=200 \mathrm{~W} / \mathrm{m}-\mathrm{K})$ is improbable.

The limited possible success for tool-based modifications led to a completely different approach that would allow the crystallinity of SL moulded parts to resemble those from metal moulds. This work focuses on another aspect of injection moulding - the moulding process rather than the tooling aspect. Two such approaches have been taken in this work. This realm of investigation was inspired by the previous DSC analysis which identified the periods of crystal formation and aided an understanding of the morphological activities that occurred during this period.

\subsection{Methodology}

\subsubsection{Material-based approach}

The first approach concerns the addition of a nucleating agent to the polymer. The development of crystalline structures is related to the speed at which the polymer is cooled from melt. Faster cooling results in a shorter period of time that the polymer spends in the transitional phase of optimum crystal development. This transitional phase is called crystallization. During this phase the polymer ceases to be amorphous (molten) and regains its crystalline structure. Crystal growth depends upon the emergence of a central nucleus to begin the growth pattern of a crystal structure. It is possible to seed the base polymer with foreign particles that provide preformed nuclei prior to the crystallization period by the addition of an additive to the polymer compound known as a nucleating agent. The preformed nuclei that are provided by the addition of a nucleating agent are independent of the base polymer crystallization and are present prior to the phase transition when the base polymer is in its amorphous state (molten). The existence of such independent nuclei allows crystal growth prior to the formation of natural nuclei by homogeneous nucleation. Growth of crystals on such foreign nuclei is known as heterogeneous nucleation. The presence of heterogeneous nuclei facilitates crystal growth which occurs sooner in the cooling period of the polymer than by homogeneous nucleation. The nylon used in the previous experiments was available from the same manufacturer with the addition of a nucleating agent and was used in the work described in this section. The material is Bergamid A65S Natural SO manufactured by PolyOne. The DSC procedure for calculation of $\chi$ was the same as that used in the previous investigations.

\subsubsection{Process-based approach}

The second approach to crystallinity control concerned an investigation of altering the injection process parameters. The initial DSC scans identified and quantified the temperature regions in which the development of crystalline content was optimum during cooling of the polymer. This was the temperature range in which the heat of fusion occurred, as shown in Fig. 7. During heating of the polymer this temperature range also represents the melting phase of the crystalline materials. The transformations that occur during the melting phase involve the breakdown of the bonds between the polymer molecules that form crystalline structures until the polymer is in an amorphous state. This transition is the opposite to that occurring during cooling where the polymer regains its structured crystalline arrangement. Thus, the heat of fusion also represents the temperature range of melting. The melt temperature setting of the injection moulding machine used in the initial experiments was $270^{\circ} \mathrm{C}$. The DSC work demonstrated that the possible temperature range that could be used was $\sim 235-280^{\circ} \mathrm{C}$ (as shown in Fig. 7). This is the critical period where $\chi$ was determined during cooling. The greater crystallinity in the parts from SL moulds was due to a longer duration spent in

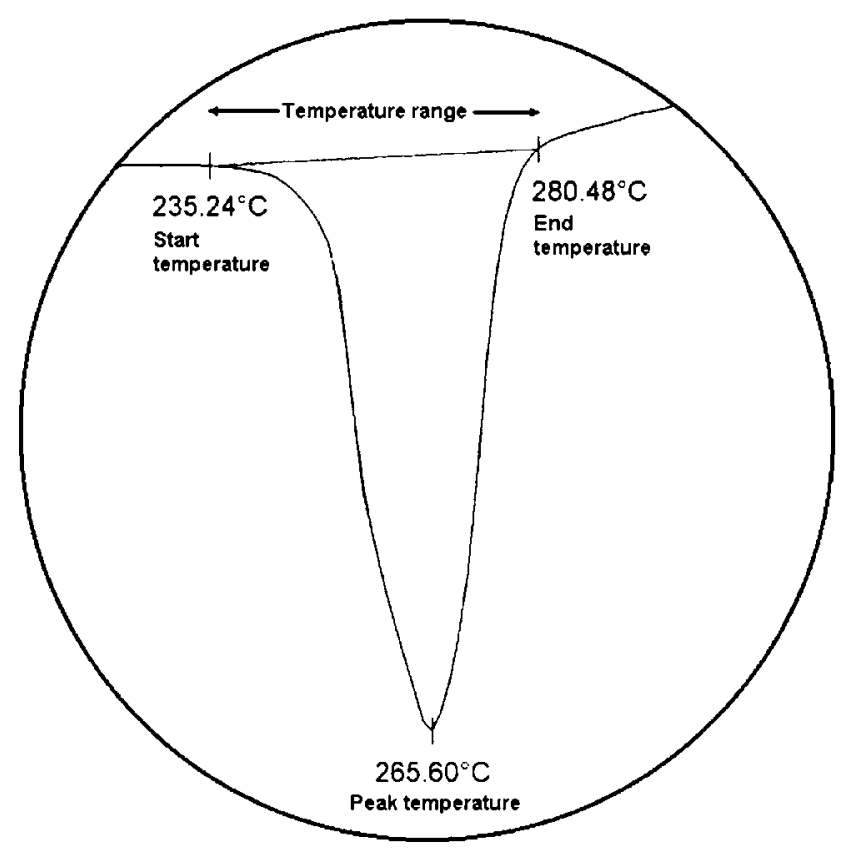

Fig. 7 Heat of fusion temperature range 
this period of crystal development owing to the much slower cooling compared with parts from AL moulds. The impetus of this section of the work was to determine if setting a lower melt temperature could effect the $\chi$ in the part by reducing the amount of time spent in the critical zone of crystal development and thereby reducing the influence of the cooling rate imposed by the mould. Any attempts to influence $\chi$ of a part must be effective during the critical temperature range of crystal development. The range was non-linear and demonstrated a temperature of optimum crystal development (see Fig. 7). This is the heat of fusion peak shown in the DSC scan. The peak melt temperature in the previous scans occurred at an average temperature of $\sim 266^{\circ} \mathrm{C}$. This indicated that the peak period of crystal development occurred $\sim 4^{\circ} \mathrm{C}$ below the polymer melt temperature set by the process in the previous experiments. In an attempt to continue a theme that may provide some correlation with previous tests, the melt temperature in these tests was set $4^{\circ} \mathrm{C}$ below the average peak temperature to $262^{\circ} \mathrm{C}$. This is illustrated in Fig. 8. The material was Bergamid A70NAT manufactured by PolyOne, the same nylon used in the previous experiments in the earlier work. The procedure for moulding the specimens and morphological analysis was the same as in the previous experiments.

\subsection{Results and Discussion}

\subsubsection{Material-based approach}

The $\chi$ results of the polymer with the addition of a nucleating agent can be seen in Table 1 . The results showed that similar values of crystallinity were developed in parts moulded from SL and AL moulds with the addition of a nucleating agent to the PA66. None of the DSC traces showed recrystallization activity. This indicates that the maximum permissible level of crystallinity existed in all

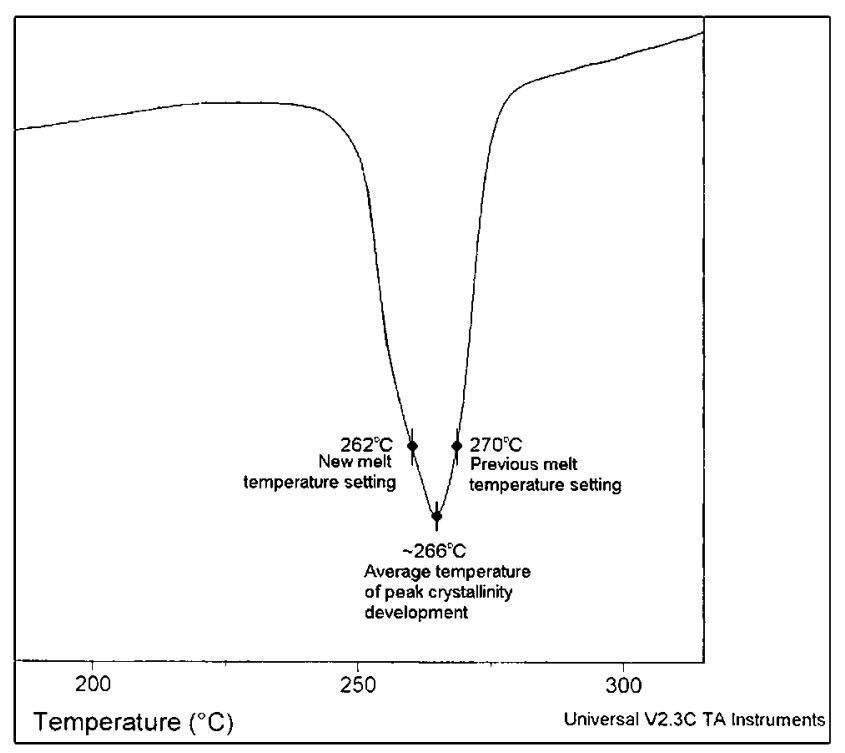

Fig. 8 Shift in melt temperature settings the samples moulded, regardless of whether they were produced in SL or AL moulds. Another characteristic exposed by the DSC scans was the temperature at which peak crystallinity activity occurred. A comparison of these results with those from the initial experiments showed that the temperature of peak crystallinity activity was higher. The previous work indicated that maximum crystallization activity temperatures occurred within a range of approximately $264-269^{\circ} \mathrm{C}$. The results of the PA66 with nucleating agent demonstrated that the same peak period occurs consistently at approximately $274{ }^{\circ} \mathrm{C}$. This indicates that crystallization activity occurred earlier during the cooling phase compared with PA66 without the addition of a nucleating agent.

\subsubsection{Process-based approach}

The results from the melt temperature modification can be seen in Table 1. Although not exactly alike, the results showed that, by lowering the melt temperature setting, it was possible to produce parts from the SL moulds that were much more similar in percentage crystallinity to those from the AL moulds compared with the initial results. The results indicated that the percentage crystallinity of the parts from $\mathrm{AL}$ moulds was unaffected by melt temperature setting variation. This may indicate that a minimum level of permissible percentage crystallinity was present in the PA66 owing to the extreme rate of rapid cooling in the AL mould. The specimens from both mould types exhibited recrystallization activity prior to the heat of fusion, showing the parts to be of a relative low crystalline content with the development of further crystallinity possible.

\section{CONCLUSIONS}

The experimental work details methods for examination and control of morphology relating to the cooling conditions. The results are applicable not only to SL moulds but also to other plastic tooling that has poor thermal conductivity. The techniques described in this work could also be applied to cast epoxy tooling.

This work has shown how DSC can be a valuable tool for establishing and quantifying the effects of process variation in injection moulding on the morphology of a part, which is critically influential on resultant part properties.

The level of crystallinity of a part dictates many of the resultant part properties. By demonstrating possible control of part crystallinity, this work has demonstrated a possible 'tailoring' of part properties. The process modifications in this work allow different morphology to be realized without changes to the machine, tool or moulded material (i.e. external cooling control, different polymer, etc). A range of achievable crystallinity would allow certain desirable part properties to be specified.

It has been demonstrated that it is possible to achieve the upper and lower limits of possible crystallinity in a part by applying differing rates of cooling. Such boundaries indicate 
the possible envelope in which the crystallinity may be varied. The differing extremes of part cooling were caused by the inherent heat transfer properties of the mould materials, $\mathrm{AL}$ giving very fast cooling, and SL producing very slow cooling.

The use of a nucleating agent provides parts that are of consistent crystallinity irrespective of the cooling rate. However, the morphology of the parts does not necessarily replicate that produced from a metal tool without a nucleating agent, and likewise is not the same as that produced from plastic tools without a nucleating agent. The consistent levels of crystallinity are in-between those previously experienced in PA66 without a nucleating agent from SL and AL moulds.

Morphology control by melt temperature alteration was indicated by the DSC results which showed the possible range of melt temperature that could be used. As this melting range is the reverse to crystal structure formation, a lowering of the melt temperature allowed a reduction in crystal formation, which resulted in lower crystallinity in the parts from SL moulds. The parts from the AL mould were unaffected by melt temperature variation. The results from the melt temperature modification, in combination with the initial results, indicate that a state of minimum permissible crystallinity was induced by the rapid cooling experienced in the AL mould. Parts from the AL moulds demonstrate low crystallinity as the zone in which crystallinity can be influenced is passed too quickly as a result of the rapid cooling, and the parts obtained achieve the same levels of crystallinity inspite of melt temperature changes. Thus, in these experiments, this crystallinity control technique has shown itself to be inapplicable to aluminium tooling. This demonstrates a case where the thermal properties of plastic tooling are advantageous. The slow cooling of the part that results from the low thermal conductivity of plastic tooling presents a unique opportunity for morphology tailoring which was unattainable in metal tooling.

\section{REFERENCES}

1 Hilton, P. D. and Jacobs, P. F. Rapid Tooling: Technologiesand Industrial Applications, 2000 (Marcel Dekker, New York).

2 Harris, R., Hopkinson, N., Newlyn, H., Hague, R. and Dickens, P. M. Layer thickness and draft angle selection for stereolithography injection mould tooling. Int. J. Prod. Res., 2002, 40(3), 719-729.

3 Palmer, A. and Colton, J. Design rules for stereolithography injection moulding Inserts. In Proceedings of Society of Plastics Engineers (SPE) Annual Technical Conference (ANTEC), New York, USA, 1999, pp. 4002-4006.

4 McDonald, J. A., Ryall, C. J. and Wimpenny, D. I. Rapid Prototyping Casebook, 2001 (Professional Engineering Publishing, London).
5 Luck, T., Baumann, F. and Baraldi, U. Comparison of downstream techniques for functional and technical prototypes-fast tooling with RP. In Proceedings of 4th European RP Conference, Belgriate, Italy, 13-15 June 1995, pp 247-260.

6 Eschl, J. Experiences with photopolymer inserts for injection moulding. European Stereolithography Users Group Meeting, Florence, Italy, 2-5 November 1997.

7 Harris, R. A., Newlyn, H. A. and Dickens, P. M. The selection of mould design variables in direct stereolithography injection mould tooling. Proc. Instn Mech. Engrs, Part B: J. Engineering Manufacture, 2002, 216(B4), pp. 499-505.

8 Harris, R. A. The injection moulding of PEEK using stereolithography moulds. RAPTIA Newsletter 7, April 2002, pp. 6-7 (Grafisk Profil, Denmark).

9 Schulthess, A., Steinmann, B. and Hofmann, M. Cibatool ${ }^{\mathrm{TM}}$ SL epoxy resins and some new applications. In Proceedings of North American Stereolithography Users Group Meeting, San Diego, California, 10-14 March 1996.

10 Jayanthi, S., Hokuf, B., McConnell, R., Speer, R. J. and Fussell, P. S. Stereolithography injection moulds for direct tooling. Solid Freeform Fabrication Symposium, Austin, Texas, 11-13 August 1997, pp. 275-286.

11 Dusel, K.-H. Materials for rapid tooling technologies. Society of Manufacturing Engineers Rapid Prototyping and Manufacturing Conference, Dearborn, Michigan, 22-24 April 1997.

12 Dawson, K. The effect of rapid tooling on final product properties. Proceedings of North American Stereolithography Users Group Meeting, San Antonio, Texas, 1-5 March 1998.

13 Damle, M., Mehta, S., Malloy, R. and McCarthy, S. Effect of fibre orientation on the mechanical properties of an injection molded part and a stereolithography-insert molded part. Proceedings of Society of Plastics Engineers (SPE) Annual Technical Conference (ANTEC), Atlanta, Georgia, 1998, pp. 584-588.

14 Birley, A. W., Haworth, B. and Batchelor, J. Physics of Plastics: Processing, Properties and Materials Engineering, 1991 (Carl Hanser Verlag, Munich).

15 Turi, E. A. Thermal Characterization of Polymeric Materials, 2nd edition, 1997 (Academic Press, San Diego).

16 Brydson, J. A. Plastics Materials, 7th edition, 1999 (Butterworth-Heinemann, Oxford).

17 Birley, A. W., Heath, R. J. and Scott, M. J. Plastics Materials: Properties and Applications, 2nd edition, 1988 (Blackie and Son Limited, New York).

18 Michaeli, W. Plastics Processing, 1995 (Carl Hanser Verlag, Munich).

19 Woodward, A. E. Understanding Polymer Morphology, 1995 (Carl Hanser Verlag, Munich).

20 Hohne, G., Hemminger, W. and Flammersheim, H.-J. Differential Scanning Calorimetry-An Introduction for Practitioners, 1996 (Springer-Verlag, Berlin).

21 Thermoplastics Collected Applications Thermal Analysis, 1998 (Mettler Toledo GmbH, Switzerland).

22 Potsch, G. and Michaeli, W. Injection Moulding: An Introduction, 1995 (Carl Hanser Verlag, Munich). 